\title{
New Record of the Non-Native Ophiothela mirabilis (Verill 1867) in St. Kitts, West Indies
}

\author{
Louis-Pierre Rich ${ }^{1 *}$, Michelle M Dennis ${ }^{2}$ and Mark A Freeman ${ }^{2}$ \\ 1Department of Marine Biology and Ecology, University of Miami Rosenstiel School of Marine and Atmospheric Sciences, Miami, Florida, United States of
} America

2Center for Conservation Medicine and Ecosystem Health, Ross University School of Veterinary Medicine, St. Kitts, West Indies

\author{
*Corresponding author: Louis-Pierre Rich, Department of Marine Biology and \\ Ecology, University of Miami Rosenstiel School of Marine and Atmospheric Sciences, \\ Miami, Florida, United States of America. E-mail: louis-pierre.rich@rsmas.miami.edu
}

Received Date: March 10, 2020

Published Date: April 29, 2020

\begin{abstract}
We describe the presence of the non-native Pacific ophiuroid species Ophiothela mirabilis on the island of St. Kitts, federation of St. Kitts and Nevis. Individuals were found in various states of asexual reproduction on common Caribbean sea fans (Gorgonia ventalina) at two locations. Definitive identification was based on morphological features and sequencing of the 18s ribosomal RNA gene. The mitochondrial C01 gene was also sequenced to assist in future Atlantic population studies of this invasive species. The coloration of the individuals as well as their current distribution suggest they are of a single lineage connected to the initial Brazilian invasion site, possibly vectored by shipping. Histological examination of $G$. ventalina tissue colonized by 0 . mirabilis found no changes to indicate direct parasite-induced damage to the host. Further study is needed to understand rate and route of invasion and the impact on its host species.
\end{abstract}

Keywords: Ecology; Gorgonian; Invasive species; Larval dispersal; Ophiuroid

\section{Introduction}

The six-armed epizoic ophiuroid Ophiothela mirabilis (Verill 1867) [1] was once restricted to the Indo-Pacific and Eastern Pacific [2,3]. Like other members of its genus, O. mirabilis undergoes asexual reproduction through fission across the disk, where daughters are produced though the regeneration of severed arms [2]. It was first described in the Atlantic sea of Brazil in 2000, and by 2012 it was also observed in the Leeward Antilles, the Windward Islands of the Lesser Antilles, and French Guiana [1,3-5].

\section{Methods and Results}

In July 2019, Ophiothela mirabilis were found in Cockleshell Bay $\left(17^{\circ} 13^{\prime} 42 \mathrm{~N}, 62^{\circ} 37^{\prime} 52 \mathrm{~W}\right)$, on the southeast peninsula of St. Kitts, in a nearshore gorgonian hard-bottom habitat. The ophiuroids were found on only five $(<5 \%)$ common Caribbean sea fans Gorgonia ventalina (Figure 1a), typically at low densities, involving less than 10 individuals per sea fan. Mouths of the brittle-stars were positioned towards the inner non-flattened (nonplanar) surface of the gorgonian branches and branchlets, in close approximation to the location of polyps (Figure 1b) [1,6]. Specimens were collected from Cockleshell Bay by taking $\sim 2 \mathrm{~cm}$ biopsies of the gorgonian host where 0 . mirabilis were present using titanium scissors. While some brittle stars fractured during sampling, morphological characteristics indicative of asexual reproduction were evident, including division in coloration, presence of underdeveloped arms, and presence of a partial disc (Figures 1c-d). The brittle stars had a disk diameter of $\sim 2 \mathrm{~mm}$, arm spines used to attach to their host, and a fused disk with multiple nodules (Figure 1d). All showed vibrant yellow-orange coloration unlike their Pacific counterparts, but similar to those in Brazil [5] and in other Caribbean sites [3,4]. Taken together, these morphological features were consistent with O. mirabilis [6].

Secondary confirmation of positive identification was performed through sequencing of the 18s ribosomal RNA gene which showed $100 \%$ match to an existing GenBank sequence from the native range of 0 . mirabilis (MH310835). Five whole brittle stars were used in separate DNA extraction representing 5 individual samples. Total DNA was extracted using a GeneMATRIX kit (EURx, Poland) following the tissue protocol. DNA was eluted 
in water and stored frozen prior to PCR amplification. For small subunit ribosomal DNA (SSU rDNA) amplification, the universal forward primers $18 \mathrm{e} 5^{\prime} \mathrm{ctg}$ gtt gat tct gcc agt and 390f $5^{\prime}$ aga ggg agc ctg aga aac g were used in combination with the reverse primer 870r $5^{\prime}$ gtt gag tca aat taa gcc gca [7]. The mitochondrial C01 gene was amplified using two primer sets: 1) LCO-ech-mf $5^{\prime}$ caa caa amc aya agg aca tcg g with C01eR1-mf $5^{\prime}$ gcw cgw gta tca acr tcc at, both modified from Layton et al $(2016)[7,8]$. C01-164echF $5^{\prime}$ agt aat ggt aac agc tca cgc a with C01-1100echR $5^{\prime}$ tat gtg tca tga agt gct ac, both designed for this study to be brittle star specific primers from known echinoderm sequences in NCBI. All PCR were performed in $20 \mu \mathrm{L}$ volumes containing dNTPs $0.2 \mathrm{mM}$, primers 0.8 $\mu \mathrm{M}$, Taq polymerase $0.02 \mathrm{U} / \mu \mathrm{L}, 2 \mu \mathrm{L} 10 \times$ buffer PCR and distilled water to achieve the correct final volume. PCR conditions were the same for all PCR reactions: initial denaturation at $98^{\circ} \mathrm{C} 5 \mathrm{~min}$, followed with 40 cycles $\left(95^{\circ} \mathrm{C}\right.$ for $30 \mathrm{~s}, 55^{\circ} \mathrm{C}$ for $45 \mathrm{~s}, 72^{\circ} \mathrm{C}$ for $1 \mathrm{~min}$ ) with a final extension at $72^{\circ} \mathrm{C} 7 \mathrm{~min}$. PCR products were purified using a GeneMATRIX PCR products extraction kit (EURx, Poland) and sent to an external lab for DNA sequencing. Bidirectional sequencing, using the same primers, was performed on all positive PCR products of the expected sizes for four individual brittle stars. All generated sequences were compared to NCBI's GenBank using the nucleotide Basic Local Alignment Search Tool (BLAST) to confirm an echinoderm origin. Sequences were then checked for chromatogram clarity using the BioEdit program [9], and then aligned using ClustalX [10]. Consensus sequences were generated by eye from the alignments and edited in BioEdit.

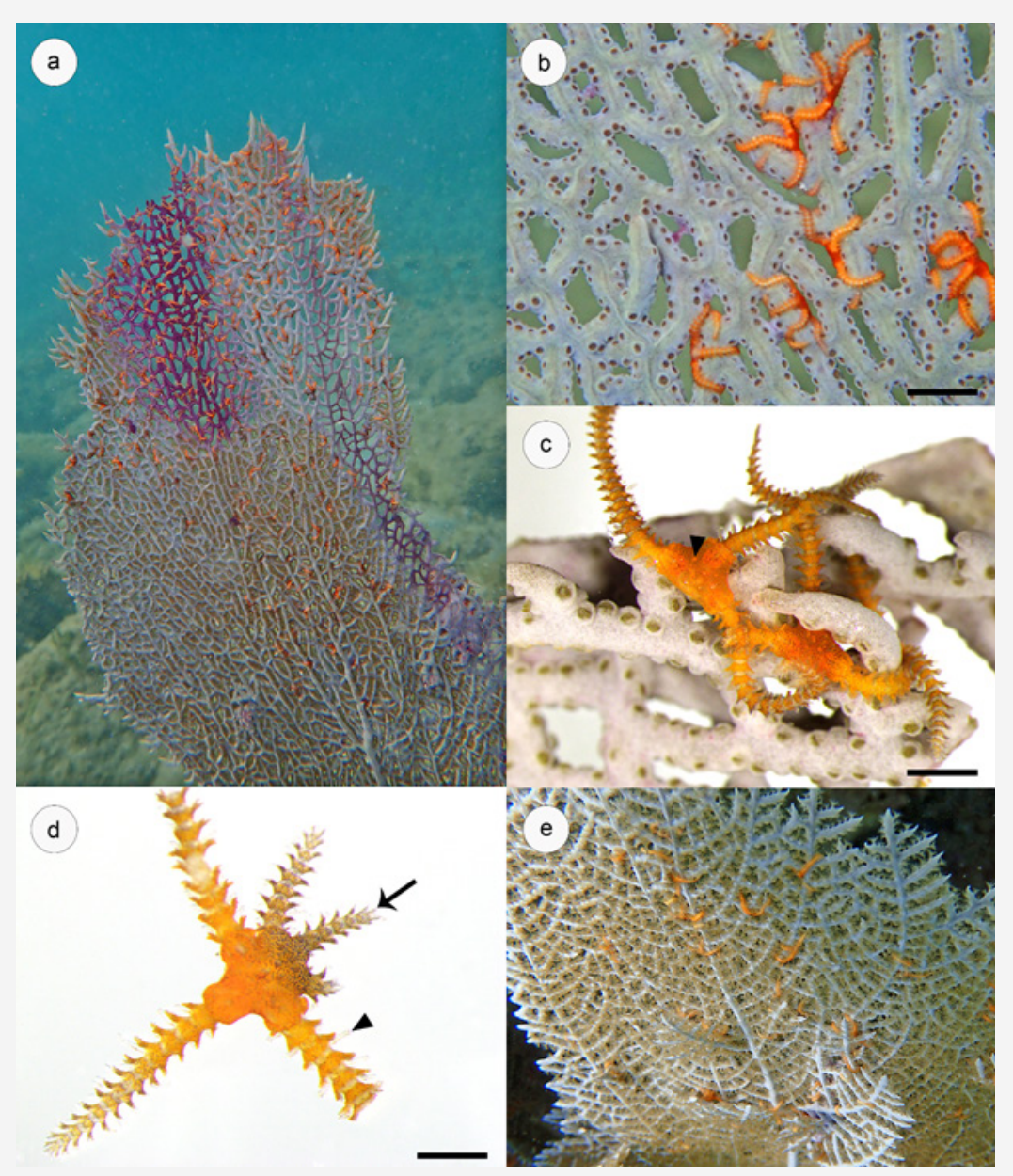

Figure 1: 1a. Gorgonia ventalina heavily colonization by Ophiothela mirabilis at Cockleshell Bay, St. Kitts, July 2019; b. Closer view of a Gorgonia ventalina heavily colonization by Ophiothela mirabilis at Cockleshell Bay, St. Kitts, July 2019. Note that mouths of the brittle-stars are positioned towards the inner surface of the gorgonian branches and branchlets where polyps are located. Bar $=2 \mathrm{~mm}$; c. Biopsy of Gorgonia ventalina including attached Ophiothela mirabilis viewed under a dissecting scope. The brittle stars have three or six arms and a $\sim 2 \mathrm{~mm}$ disc with small nodules (arrowhead). incomplete discs indicate recent fission. Bar $=1.5 \mathrm{~mm} ; \mathrm{d}$. Ophiothela mirabilis viewed under a dissecting scope. Note differential coloration and presence of underdeveloped arms (arrow) indicative of asexual reproduction. Arrowhead indicates arm spines. Bar = 1mm; e. Gorgonia ventalina heavily colonized by Ophiothela mirabilis at Shitten Bay, St. Kitts, November 2019.

For the mitochondrial CO1 gene, both sets of primers successfully amplified the target gene which enabled us to build a robust consensus sequence of 1070 base pairs from 4 of the 5 extracted individual DNA samples. This sequence was most similar to Ophiothela spp. in BLAST searches, being $98.69 \%$ similar to $O$. vincula over the entire sequenced region of 1070 bases. For the SSU rDNA, a consensus sequence of 1169 base pairs was constructed from amplifications from 4 of the 5 brittle stars. This sequence was $100 \%$ identical to the sequence for Ophiothela mirabilis (MH310835) over 692 bases of comparable sequence data. All 
sequences generated in this study have been submitted to Genbank with the accession numbers MN961481.

One biopsy of apparently healthy sea fan tissues with attached O. mirabilis was immersed in Z-Fix (Anatech Ltd) diluted 1:5 with seawater. The biopsy was decalcified using Formical 2000 (StatLab, McKinney, TX) 48 hours post fixation, then processed routinely for histology, embedded in a planar orientation in paraffin wax (i.e. oriented so that sections were parallel to the face of the sea fan), sectioned at $4 \mu \mathrm{m}$, and stained with hematoxylin and eosin. No microscopic pathology was identified in sea fan tissues associated with the brittle star.

Cockleshell Bay was surveyed again in November, 2019, and o. mirabilis persisted at roughly similar prevalence and intensity among sea fans. During this time, the brittle stars were also

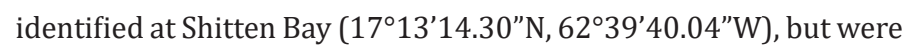
not identified at Turtle Beach $\left(17^{\circ} 14^{\prime} 03.26^{\prime \prime} \mathrm{N}, 63^{\circ} 37^{\prime} 38.81^{\prime \prime} \mathrm{W}\right)$, Majors Bay $\left(17^{\circ} 13^{\prime} 19.11^{\prime \prime} \mathrm{N}, 62^{\circ} 38^{\prime} 49.80^{\prime \prime} \mathrm{W}\right)$ or White House Bay (17 $\left.14^{\prime} 58.78^{\prime \prime} \mathrm{N}, 62^{\circ} 39^{\prime} 30.79^{\prime \prime} \mathrm{W}\right)$. At Shitten Bay, the majority of sea fans were colonized by the brittle stars.

\section{Discussion}

The observation of $O$. mirabilis in Kitts represents its northernmost occurrence in the Caribbean Sea and the first report of its invasion in the Leeward Islands of the Lesser Antilles. The apparent spread to St. Kitts raises concern for its undetected presence in surrounding islands and risk for full colonization of the Greater and Lesser Antilles. There are two primary mechanisms hypothesized for the spread of 0 . mirabilis throughout the Atlantic including ship-borne [3,4] and planktonic larval dispersal [4,11]. Hendler and Brugneaux (2013) hypothesized that immediate spread to the Leeward Islands of the Lesser Antilles would indicate ship-borne dispersal rather than by oceanic circulation because surface flow around St. Vincent, the nearest reported invaded site, moves towards southern Caribbean areas. Interestingly, the two colonized sites in St. Kitts have high recreational boat traffic relative to other non-colonized sites surveyed on the southwest peninsula, one being a hub for water taxi service to Nevis, the other being a target location for chartered catamaran tours.

Morphologic plasticity complicates the taxonomy of Ophiothela period to abbreviation, [11]. However, the coloration of 0 . mirabilis in St. Kitts was similar to that observed on other Atlantic and Caribbean locations, reinforcing the hypothesis that individuals descended from a single common lineage, first observed in Brazil [3]. Reproduction is believed to be predominantly fissiparous and asexual, resulting in clonal progeny which could facilitate a molecular approach to studying geographical spread. We sequenced the mitochondrial C01 gene in order to aid future studies examining possible clonal populations of invasive 0 . mirabilis, their pattern and route of spread, and whether single or multiple invasions have occurred in the Caribbean region. In addition, specific primers have been designed to allow better amplification of the CO1 gene of $O$. mirabilis to aid in research and management across the region.
At present, limited knowledge on the biology of 0 . mirabilis precludes any meaningful speculation on its impact to the invaded range. The number of $O$. mirabilis colonizing some sea fans in St. Kitts resembles the density with which they are observed on gorgonians in their native range [6]. This density of host colonization is hypothesized to negatively impact host autotrophy and fitness [1], although interactions with the host species have been poorly studied. We histologically examined tissues of $G$. ventalina to which $O$. mirabilis were attached and found no changes to indicate direct parasite-induced damage to the host. However, colonization may impact host health indirectly, and associations among colonization and prevalence of mortality or disease in the host species should be addressed with future research. In Brazilian waters, 0 . mirabilis is an epizoite on at minimum 29 individual host taxa [5], a majority of which are present in St. Kitts. In contrast, O. mirabilis has so far only been observed on $G$. ventalina in St. Kitts, potentially representing a host preference or an early stage of invasion where other hosts have not yet been colonized. There is a paucity of data on the rates of colonization in the Windward Islands as well as any ecosystem effects since their initial reporting. Longitudinal surveys of hardbottom gorgonian habitat should be undertaken in St. Kitts and the Windward Islands in order to determine the true rate of invasion and host impact.

While the consequences of invasive 0 . mirabilis are presently unknown, marine invasive species have impacted biodiversity, environmental, and economic outcomes worldwide [12]. Further study is needed to understand possible impacts of invasive $O$. mirabilis on Caribbean reefs and to identify mitigations which effectively limit its spread. Nearby islands should be aware of its presence to enable early detection and to identify most susceptible host species.

\section{Acknowledgements}

The authors thank Rob and Kathleen Gilbert for their assistance with surveys.

\section{Conflict of Interest}

On behalf of all authors, the corresponding author states that there is no conflict of interest.

\section{References}

1. Thé J, Oliveira M, Matthews H, Correia F (2018) The invasive brittle star Ophiothela mirabilis Verrill, 1867 (Echinodermata, Ophiuroidea) in the southwestern Atlantic: filling gaps of distribution, with comments on an octocoral host. Lat Am J Aquat Res 46: 1123-1127.

2. Clark AM (1976) Tropical Epizoic Echinoderms and their Distribution. Micronesica 12: 111-117.

3. Hendler G, Baldwin CC, Smith DG, Thacker CE (1999) Planktonic dispersal of juvenile brittle stars (Echinodermata: Ophiuroidea) on a caribbean reef. Bull Mar Sci 65: 283-288.

4. Hendler G, Brugneaux SJ (2013) New records of brittle stars from French Guiana: Ophiactis savignyi and the alien species Ophiothela mirabilis (Echinodermata: Ophiuroidea). Mar Biodivers Rec 6: 1-6.

5. Mantelatto MC, Vidon LF, Silveira RB (2016) Host species of the non-indigenous brittle star Ophiothela mirabilis (Echinodermata: Ophiuroidea): an invasive generalist in Brazil? Mar Biodivers Rec 9: 1-7. 
6. Granja-Fernández R, Herrero-Pérezrul MD, López-Pérez RA, Hernández L, Rodríguez-Zaragoza FA, et al. (2014) Ophiuroidea (Echinodermata) from coral reefs in the Mexican Pacific. Zookeys 406: 101-145.

7. Freeman MA, Anshary H, Ogawa K (2013) multiple gene analyses of caligid copepods indicate that the reduction of a thoracic appendage in Pseudocaligus represents convergent evolution. Parasites \& vectors 6(1): 336.

8. Layton KK, Corstorphine EA, Hebert PD (2016). Exploring Canadian Echinoderm Diversity through DNA Barcodes. PloS one 11(11): e0166118.

9. Hall T (1999) BioEdit: a user-friendly biological sequence alignment editor and analysis program for Windows 95/98/ NT. Nucleic Acids Symp Ser 41: 95-98.
10. Thompson JD, Gibson TJ, Plewniak F, Jeanmougin F, Higgins DG (1997) The CLUSTAL-X windows interface: flexible strategies for multiple sequence alignment aided by quality analysis tools. Nucl Acids Res 24: 4876-4882.

11. Hendler G, Migotto AE, Ventura CRR, Wilk L (2012) Epizoic Ophiothela brittle stars have invaded the Atlantic. Coral Reefs 31: 1005-1006.

12. Molnar JL, Gamboa RL, Revenga C, Spalding MD (2008) Assessing the global threat of invasive species to marine biodiversity. Front Ecol Environ 6: 485-492. 